\title{
Collaborative virtual reality application for interior design
}

\author{
Haziq Izwan Rahmat, Suzana Ahmad, Marina Ismail \\ Faculty of Computer and Mathematical Science, Universiti Teknologi MARA (UiTM), Malaysia
}

\begin{tabular}{|c|c|}
\hline Article Info & ABSTRACT \\
\hline Article history: & \multirow{8}{*}{$\begin{array}{l}\text { Virtual reality (VR) is currently popular technology that has been used by } \\
\text { people in various areas such as architecture, medical, training and many } \\
\text { more. In this paper, the researcher proposed collaborative VR for interior } \\
\text { design that allows customer and designer work together at different location. } \\
\text { Commonly, the designer draw their design in two-dimensional (2D) graphics } \\
\text { at the drawing paper and presents to the customer. However, 2D drawings } \\
\text { led to an ambiguity, indistrinct and uncertainty on the design. In addition, } \\
\text { redesign any changes lead to re-build the prototype. These will be costly and } \\
\text { wasting time, therefore, researcher proposed collaborative VR application } \\
\text { which provide an intense feelings about the design which is presented in } \\
\text { form of three-dimensional (3D) graphics. Additionally, proposed application } \\
\text { would allow the designer and customer to work in real-time. In conclusion, } \\
\text { collaborative VR will give the benefits for interior design manufacturing to } \\
\text { prosper along with current technology. }\end{array}$} \\
\hline Received Jan 12, 2019 & \\
\hline Revised Apr 6, 2019 & \\
\hline Accepted May 15, 2019 & \\
\hline Keywords: & \\
\hline Virtual reality & \\
\hline Collaborative system & \\
\hline Interior design & \\
\hline
\end{tabular}

Copyright () 2019 Institute of Advanced Engineering and Science. All rights reserved.

\section{Corresponding Author:}

Haziq Izwan Rahmat,

Faculty of Computer and Mathematical Science,

Universiti Teknologi MARA (UiTM),

Shah Alam, Selangor, Malaysia.

Email: haziqizwanrahmat@gmail.com

\section{INTRODUCTION}

Computer graphic provide human with workspace that deals with the creation and manipulation of digital image. Particularly, Virtual reality (VR) technology is an extension to 3D computer graphics that capable to transform and renovate the whole world in the 21st century [1-3]. VR offer virtual environment that can be same as actual world. Over recent years, VR technology has been implementing in the area of architecture, especially in the interior design and decoration. VR technology provides customers and designers to get a clear and intense feeling about the interior design that has been designed [4]. Through VR technology, the designers are able to participate in 3D environment which provide an interaction, immersion and real-time [4-5]. However, the demand to implement VR technology in the area of architecture especially interior design is less because there is not much interest among researchers. So that, VR is not a tool for assist in design area, but it is only an approach to demonstrate the design [6].

In the beginning of interior design project, neat planning is needed for the designers to begin their project after discussion with the customer. The designers must be creative and smart to come out with brilliant ideas about the design in order to follow on customer demands. They must know the concept of design in order to make their design have some criteria such as safety, comfortable and more. This conceptual development is the most important part and should be emphasized since it will give the significant impact on the design and customer requests [3]. Usually, they will draw their design on the paper that will produce two-dimensional (2D) graphics or flat images which sometimes can make the design indistinct and uncertainty [2]. In addition, redesign any changes lead to re-build the actual prototype of interior design that will be costly [4] and wasting time. Furthermore, the location of the designers themselves 
is a problem. A good designer may not be available nearby. Sometimes, the designer may need to meet the customer frequently for further discuss in order to fulfill the demand from customer. Frequent meetings with a good designers that lives far away will incurred higher cost. By having collaborative VR application, the problem with different location can be solved.

Collaborative work gives an advantage especially in quality and performance of work. In computer, the concept of collaboration which supported cooperative work (CSCW) is used in various areas especially for the application [7]. The examples of application that used collaborative concept are Whatsapp, Gmail, Facebook, and so on. The concept of collaborative is shown for this application is allowing chatting, e-mail, and direct message. Meanwhile, this concept can be integrate with VR, which multiple users can be placed together to performs their work in the place that known as Collaborative virtual environments (CVE). CVE allows user from the different location to be access and shared the virtual environment with another user [8]. In recent years, many researches have done on CVE, especially focusing on technical problems and interactions. Existing CVE and CSWE does not provide suitable platform for an interior design manufacture. The idea of CVE can change the working style of an interior designer into the used of the new and modern technology.

In this paper, the researcher proposed the concept of collaborative VR application for interior design area. The implementation of collaborative VR application allows customers and designers to work together in the application. The application will used supportive input device together with an additional devices that known as hand gesture recognition devices. The rest of the paper is structured as follows: Section II that will discuss on literature review, Section III describes the proposed design of this research, and the last section, Section IV will conclude the whole paper.

\section{LITERATURE REVIEW}

Explaining research chronological, including research design, research procedure (in the form of algorithms, Pseudocode or other), how to test and data acquisition [6-9]. The description of the course of research should be supported references, so the explanation can be accepted scientifically $[4,10]$.

\subsection{Virtual reality}

Interactive computer graphics has become valuable mediums for delivering information in various fields such as architecture, science, engineering, medicine, business, entertainment, education and training [9]. This technique manipulates images and drawings in two-dimensional (2D) and three-dimensional (3D) displays. Thereby, VR technology is part of a computer graphics technique used to form the realistic simulation of 3D environments that unify with computer techniques such as Computer Human Interaction (HCI), sensory technique, Artificial Intelligent (AI), and robotics [4][10], together with display technology which allows a user to interact with those environment [11]. VR offers the virtual world to people where it can be the same as an actual world [4]. From the other perspective, VR is an innovation that enable people to build an environments and communicate with any object in those environment by real time, and has been broadly utilized for teaching and learning purposes [11]. Nowadays, the technology of VR is become popular among people since it can be a tools to help them in many domains. As mention earlier, HCI concept can be form through VR technology that integrate with modern interactive devices such as face and gesture recognition devices, haptic sensors, and tracking devices in order to provide flexibility in the application [12].

According to Sherman and Craig [13], there are four (4) basic elements for VR which are interactivity, virtual world, immersion and sensory feedback. First, the intended interactivity is the reaction that occurs in the virtual world through the user action. An interactive environment allows users to move around in a virtual space and interact with objects, characters and places [14]. Second, the element of virtual world that can be classified as the world with objects and principles of space. Apart from that, other views about virtual world is a space or environment that exists in the mind of a creator and will broadcasts the space to others. For example, the space in the game and the movie. Third, an immersion means the user will be immersed in virtual environment that has been created. Sensibility of environment allows users to lives within the environment and able to sense surrounding objects such as the actual world. The last element which is sensory feedback can be describe as feedback that generated based on user input. It allows users to set their body position and choose their point of view that can influence the actions in virtual world.

\subsection{Interior design}

Interior design is an architectural branch that involves with indoor living space and a design that focused on environmental space [15-16]. Meanwhile, the meaning of interior design based on Wikipedia is an art and science to improve the building that focuses on interior part to provide a healthier, comfortable and increase the quality of life for the persons using the space. The objectives of constructing interior design is to 
build a functioning and aesthetic space for private, working or public spaces [15]. Another objectives is to ensure the safety of users or customers from any dangerous objects or external factors such as weather.

In a different perspective, the main objective of interior design is to meet customer needs and demands that can contribute to the successful project. Thus, this profession is usually managed by an interior designer who has the ideas, plans, research, and managing a project. Commonly, interior design project is presented by interior designer in the form of hand sketching according to customer demands through their creativity and ideas [17].

\subsection{Interior design based on virtual reality}

In era of "Digital World", the use of digital technology such as computers has been widely used in various fields. Digital technology usage has now become a trend among people that can influenced social development [17]. Alongside this development, the area of architecture especially in the interior design has made a consideration that digital technology as the modern design techniques for designing building structures either internal or external and acquit from the traditional design techniques which is hand drawing the plan on paper [17]. This models and drawings are need to be draw again due to the changing requests from customer [17-18]. Besides, hand drawing features have some limits which customer are not able to see the entire space of the design and commonly shown only a part of the point of view [17].

To mitigate the problems that happened as mention before, virtual reality (VR) technology which is part of the computer graphics techniques was introduced in various field especially in the area of architecture that include an interior design. In this area, VR was used as the approach for demonstration [6]. VR has produce the application that contains an interface in form of 3D and allows an interactivity between the user and computer. The interactivity within the VR scene usually used some input devices such as keyboards and mice. However, these interactions can be enhanced through the utilization of gesture recognition. Through this technique, designers can design and decorates in virtual spaces or room according to their ideas or plans that has been made with customer, and any changes can be made in those virtual space in order to achieve the level of satisfaction between designer and customers [6]. Furthermore, customers can also view the desired design within the virtual room before deciding to choose the design that satisfy their needs. The designers give an attention towards VR technology and make initiative for their project as a tool to better view and comprehend the design.

\subsection{Related research on collaborative virtual reality}

This research is focuses on collaborative VR application for domain of interior design. Comparison had be made to ensure the research is not exactly same as proposed application. The related research can be shown in Table 1. In the table provides a year that the research has been conducted, the authors, contents, domain, and techniques.

Table 1. Related research on collaborative virtual reality

\begin{tabular}{|c|c|c|c|c|}
\hline Year & Authors & Content & Domain & Technique \\
\hline 2018 & Huan Zhao et al. [19] & $\begin{array}{l}\text { Train the autism children to play the games using } \\
\text { hand gesture in VR }\end{array}$ & Training & $\begin{array}{l}\text { Interactive games in } \\
\text { collaborative VR }\end{array}$ \\
\hline 2018 & Gyongyi et al. [20] & $\begin{array}{l}\text { Creating skills for students on their creativity, } \\
\text { creation and innovation using VR techniques }\end{array}$ & Education & $\begin{array}{l}\text { Immersive } \\
\text { Collaborative VR }\end{array}$ \\
\hline 2017 & Kaleja and Kozlovska [21] & $\begin{array}{l}\mathrm{VR} \text { as an approach of interior design with } \\
\text { supporting hardware and software }\end{array}$ & Architecture & Immersive VR \\
\hline 2017 & Chalil Madathil et al. [22] & $\begin{array}{l}\text { Developed collaborative VR system for moderated } \\
\text { remote usability testing laboratory }\end{array}$ & Training & Collaborative VR \\
\hline 2015 & Sharma et al. [23] & $\begin{array}{l}\text { Performing virtual online campus tours and } \\
\text { evacuation drills }\end{array}$ & Training, Safety & $\begin{array}{l}\text { Immersive } \\
\text { collaborative VR }\end{array}$ \\
\hline 2015 & Pick et al. [24] & $\begin{array}{l}\text { Established factory planning workflow without } \\
\text { disruption }\end{array}$ & Industrial & $\begin{array}{l}\text { Immersive } \\
\text { collaborative VR }\end{array}$ \\
\hline 2014 & Prabal et al. [25] & $\begin{array}{l}\text { Providing new method of Advanced Cardiac Life } \\
\text { Support (ACLS) training to care provider }\end{array}$ & Training & Collaborative VR \\
\hline 2009 & Lee et al. [7] & $\begin{array}{l}\text { Solve the time conflicts between researchers from } \\
\text { different regions }\end{array}$ & $\begin{array}{l}\text { Biology/ } \\
\text { Science }\end{array}$ & Collaborative VR \\
\hline 2008 & Strelzoff et al. [26] & $\begin{array}{l}\text { Construction Scheduling to help people with } \\
\text { mental health issues }\end{array}$ & Health & $\begin{array}{l}\text { Collaborative VR, } \\
\text { games }\end{array}$ \\
\hline
\end{tabular}

In research that conducted by Huan Zhao and his members [19], they founded that collaborative VR can be used in training domain through an interactive games. The games is allow two children to play the 
games by using hand gesture that move the objects in VR with collaboratively. Besides, the purpose is to encourage natural communication and the teamwork in the games [19].

Kaleja and Kozlov [21] used VR as an approach for interior design. They developed the system that implement dynamic real time visualization (DRTV) [21]. DRTV supported by special devices in order to represent the design and controls the system. The special devices used for this system is Head Mounted Display (HMD) and controller. The system is using immersive VR technique that run on mobile that applying at HMD devices. The system is created by using Unity3D software. The research is cover o architecture domain which is an interior design. However, the system is not applying collaborative work and different on purposes.

The work by Gyong yi and friends [20] at the year of 2018, they proposed the work that implement the approach of collaborative VR to create technical skills or ability for the students especially in creativity, creation and innovation [20]. The work is used the technique of collaborative VR that has been developed using MaxWhere, which is an immersive VR system that provides cognitive process and enhancing creative thinking. This work is cover on the domain of education which the most users are Computer Science (CS) students. Meanwhile, in 2017, Chalil Madathil with his friends [22] developed collaborative VR system for moderated remote usability testing laboratory. The system allow participants and facilitator to work at the different location. The researchers compared their system with two method which is traditional methods and WebEx which is two-dimensional (2D) web-based screen sharing and conferencing methods. This system is made by using Java code that connecting with the internet. The system is for training purposed.

According to Sharma et al. [23], their research is cover on domains of training and safety. The purpose of the research is to performing virtual online that used immersive collaborative VR technique for campus and tours and evacuation drill which using special devices, Oculus Rift. Next, the work from Pick and friends [24], they have proposed the research which implementing immersive collaborative VR for factory planning process. The topics cover on domain of industrial. This research purpose is to conduct the benefits of virtual walkthroughs that using a CAVE to an established factory planning workflow without disrupting it. The used techniques are integration of collaborative VR with immersive VR that runs on CAVE.

In research by Prabal et al. [25], they proposed new approach which is collaborative VR for advanced cardiac life support (ACLS) training to care provider in order to overcome the challenges and disadvantages of traditional training methods. The research cover on training domain. The system used collaborative VR techniques that implement the same concept as face-to-face method. Besides, the researcher made the comparison between traditional methods used for ACLS training with their system that measured in term of performance and effectiveness [25]. The system has been build using Second Life that provide 3D environment, objects and interaction for interfaces. Furthermore, the article by Lee et al. [7] which cover on science and biology domain. The authors mentioned their purpose to designed the application which to solve the time issues between researchers from different regions. The application used collaborative virtual reality environment (CRVE) in molecular biology that provide users with virtual experiences in virtual spaces [7].

Strelzoff and his partners [26] are proposed the research about collaborative VR combining with game that aims to construct scheduling for helping an individual with mental health issues. This research is cover on healthy domain. The game will provide learning process that can help to overcome some mental issues. It used the method of Second Life which was virtual world on internet [26]. In conclusion, it is clear that the domain of interior design is not being explored yet. All of the related research are cover on different domain such as healthy, biology or science, industrial and so on. However, there have several research that used the same technique which is collaborative VR system that allow multiple users to interact with the virtual environment or interfaces. Meanwhile, there are certain research that used interactive games platform in order to enhance their application and achieve their own goals.

In conclusion towards several related research, the researcher have found that majority of related research are cover on different domain such as training, education and many more. Meanwhile, there is only one research that cover on architecture domain, but the researchers [20] not applying the concept of collaborative VR. This give an opportunity for the research to proposed the application of collaborative VR for architecture especially in interior design. The proposed application is different form all the related research since the proposed application cover on interior design which not has been covered by majority of researchers.

\section{PROPOSED APPLICATION}

Overall process to develop the application will be emphasized where consists of several sub-topics such framework, architecture, and flowchart. Each of this sub-topics contains the description that will explain about the elements involved and the flow of the process: 


\subsection{Application framework}

In this research, framework has been drawn in order to describe the system functionality that connected with user and designer by using the computer science technique and tools. The framework for this research consists of users which refer to customer and interior designer, input devices, database, 3D interfaces, and computer.

The application allow customer and designer to work simultaneously which means both of them can design and edit their work in real-time. This allow an interaction between both users in the application even through a long range. Users will used an input devices to connect with computer and interact with the interfaces of the application. In this research, input devices can be used is mouse, keyboard and hand gesture recognition devices. Hand gesture recognition devices are modern technology of input devices that can support VR interfaces or 3D environment [27]. Leap Motion is hand gesture recognition devices that will be used by user in this research to interact with the interfaces.

The interface of this application will used VR interfaces consists of 3D environment and objects. This application used as a prototype before both users proceed to their real project. Through this method, the traditional method will be changed to modern method which designer usually used the technique of hand drawing the design on drawing paper, into used technology as a tools to create their design. Figure 1 show the framework for this application that can describes the relationship between all elements.

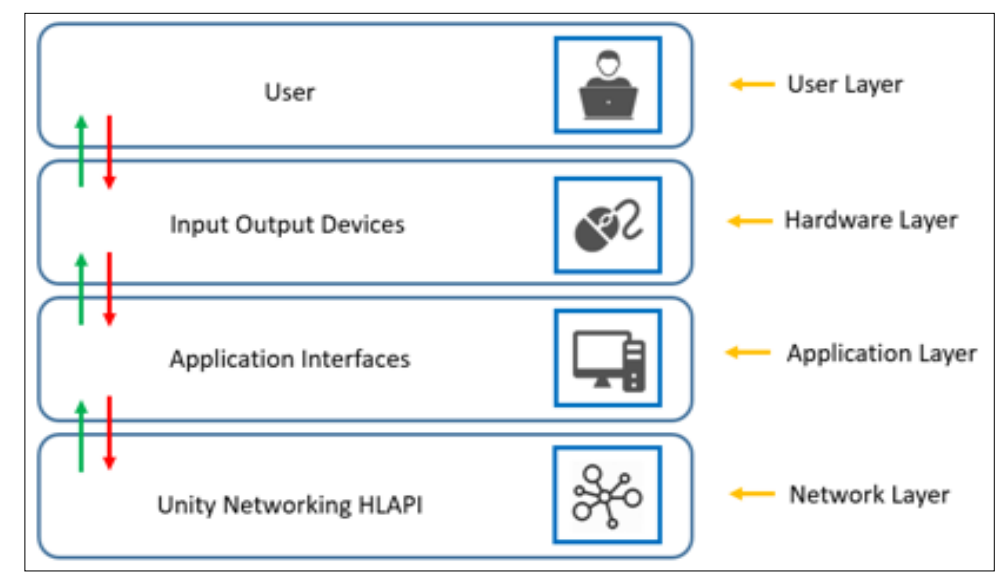

Figure 1. The framework for this application that can describes the relationship between all elements

The interfaces will be developed using powerful software for creating 3D environment which is Unity 3D. Unity has the tools or packages to create collaborative interfaces system which allow multiple user to work together in real-time. The computer required an internet to connect with the database and retrieve the information. In this application interfaces, it will used an interactivity elements that allow the system to triggered the actions from user and ensure that the result will be followed according to user actions.

The user can interact with the application using input devices such as keyboard and mouse. The monitor will be the output the application interface to the users. Next, application interfaces acts as communicator between user and application. Meanwhile, the Unity Networking HLAPI is a new set of networking instructions constructed into Unity3D used by application to form the real-time application that allow multiple user to work in single virtual environment.

\subsection{Application architecture}

Application architecture describes the structure and views of the system. Besides, it can be composed of component systems that will work together to create a full system. In this research, the application architecture can be shown at Figure 2. This architecture includes the components of users which is designer and customer, input devices, VR interfaces, computer and database.

The process begin with either designer or customer known as user A and user B will input by using an input devices such as keyboard, mouse and hand gesture recognition devices. When users enter the input from any devices, the requests data has will be submitted form the devices through the VR interfaces that will display by computer. VR interfaces will submitted through the computer to generate the data. Computer provides the techniques to manipulate graphics data which known as computer graphics. VR is one of the computer graphics techniques that will manipulated the data from the VR application interfaces. 


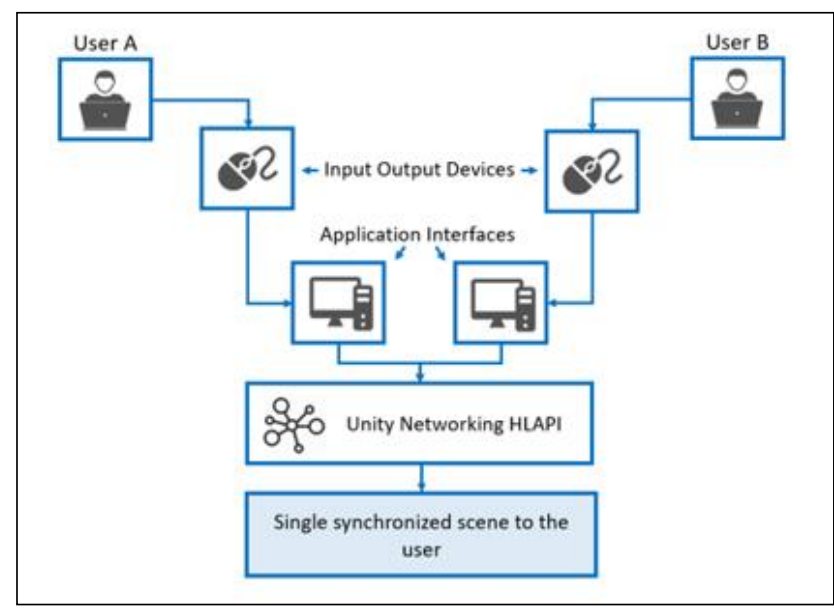

Figure 2. The application architecture that shows the components that related to each other to describe the overall system

The users A and user B have similar scenes one the application. In order to allow the designer and customer work simultaneously, they need to create a room to allow multiple users to enter. The users need internet connection and one of them need to be a server. When server is ready, another users can enter the room that has been created by server. The application used Unity Networking HLAPI concepts, which the clients can connects the server through the host server based on local IP address. After the client connected, the application will provide a single synchronized environment to the customer and designer that enables to interact and works on that environment. The users can also send and receive the 3D object transformation on the environment to change the object's position on both server and client sides. Which means user A and user $B$ will share the same scene that has been created by server among them.

\subsection{Application flowchart}

Flowchart shows in form of diagram that regarded as workflow or process of the system. Flowchart used for analysis, designing, and documenting a simple programs. A simple flowchart will be show in Figure 3 that describes the flow process of collaborative VR application. The application will begin with displaying the user interfaces that in form of 2D graphics. 2D graphics is used for main menu which consists of button and text. The application will used audio background in order to make it more attractive. Users have a choice which is begin their editing, displaying the descriptions and end of the system.

First, if the users choose to display the descriptions, then the application will display the descriptions in form of text. So that, the users can read all of the system's instructions that must followed by users. Users is provided button back to go to the main menu. Second, if users choose to start editing or designing, it will enter the process of editing. In this process, there have 5 choices which input objects, input color, removing process, display design and end process. Users can decide which choices they want. When users input the objects, the objects that provided in Unity will enter in 3D environments. All objects including 3D objects such as downloaded assets, 3D shapes, environment and terrain. All objects for interior design can be provided by download the assets either in Unity Asset Store or download at website that provide 3D objects. For input color, users are allow to add the texture in 3D objects or the environment. Color is the important elements to make the design look interesting and not dull that less attractive. Meanwhile, process of removing allow users to remove objects and color if they do not want or making any mistake such placing the wrong objects at place. After that, users can display the design that has been created before making any decision. Also, users are allows to end the process if they decided not to continue or exit from the application.

Third, users are allow to end the process if they decided not to continue the process. The flowchart shows all the important process that have in this application. The process can be done by users which is customers and designers. Both of them can do the same things since this application is collaborative that can synchronize their work in real-time. 


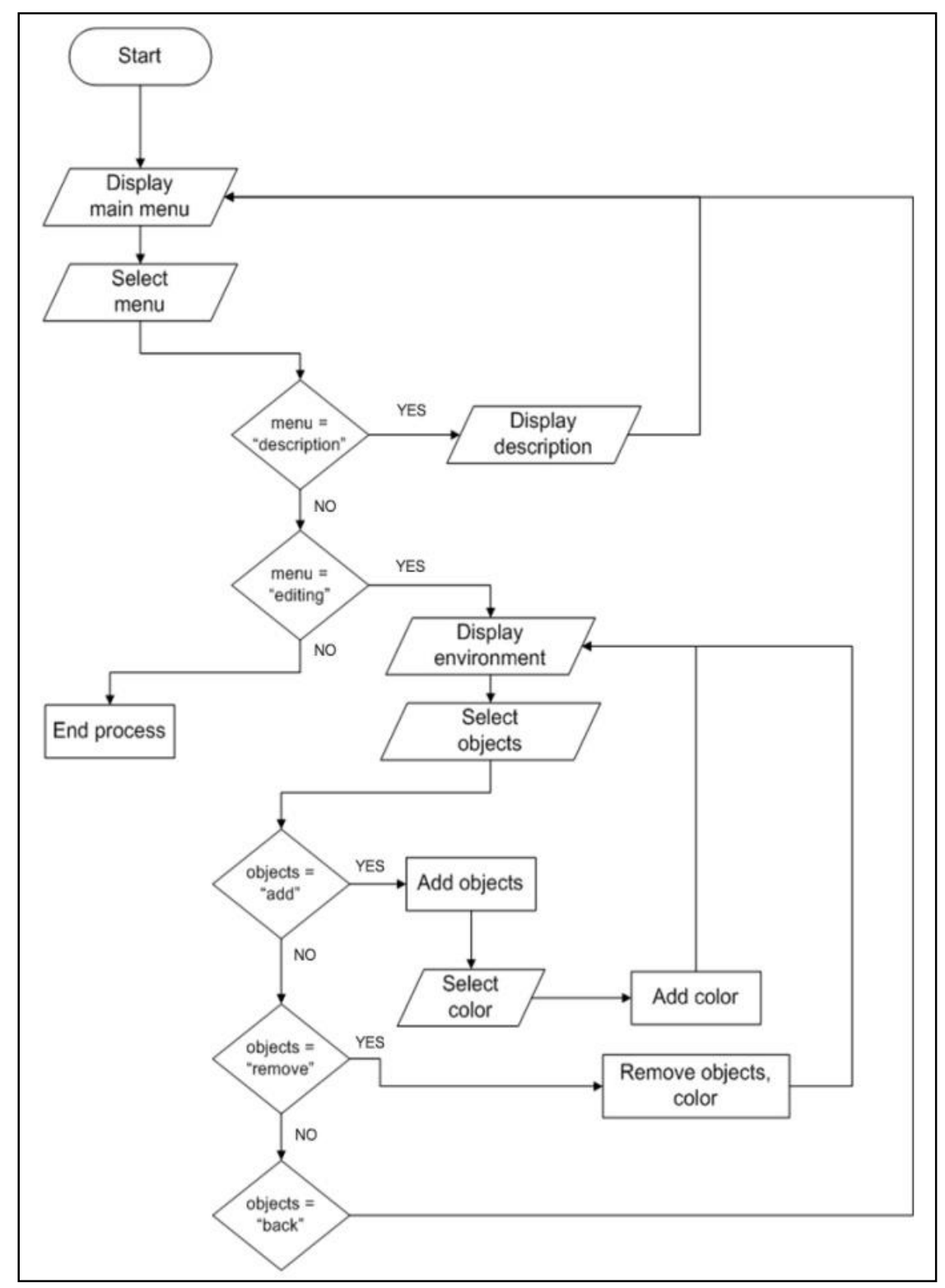

Figure 3. The flowchart that show the process and workflow of the application

\section{CONCLUSION}

This paper presents the development of the collaborative VR application for interior design manufacture. The application allows customer and designer to work together in real-time. The customer can see the design by the designer and can make any editing directly through the application. Furthermore, VR offers virtual environment that can make the customers visualize the real environment of the design and helps the customer in decision making before the designer begin to build the actual prototype. The proposed application can cut the budget for designers and customers. Customers and designers can work together in which any changes on the design can made through the proposed application. In conclusion, proposed application helps in the platform of interior design manufacturing to prosper along with current technology.

\section{REFERENCES}

[1] A. Saeed Alqahtani, L. Foaud Daghestani, and L. Fattouh Ibrahim, "Environments and System Types of Virtual Reality Technology in STEM: A Survey," Int. J. Adv. Comput. Sci. Appl., vol. 8, no. 6, pp. 77-89, 2017.

[2] F. Sun, Z. Zhang, D. Liao, T. Chen, and J. Zhou, "A lightweight and cross-platform Web3D system for casting process based on virtual reality technology using WebGL, " Int. J. Adv. Manuf. Technol., vol. 80, no. 5-8, pp. 801816, 2015. 
[3] S. Wang, J. Ying, L. Wei, S. Li, and J. Jing, "Effects of parasagittal meningiomas on intracranial venous circulation assessed by the virtual reality technology, "Int. J. Clin. Exp. Med., vol. 8, no. 8, pp. 12706-12715, 2015.

[4] J. Li, "Interior Design Method Based on Virtual Reality Technology," 2016 Int. Conf. Intell. Transp. Big Data Smart City, pp. 229-232, 2016.

[5] J. C. Yang, C. H. Chen, and M. Chang Jeng, "Integrating video-capture virtual reality technology into a physically interactive learning environment for English learning," Comput. Educ., vol. 55, no. 3, pp. 1346-1356, 2010.

[6] P. Su and S. Wang, "Virtual reality practice in architecture design," Proc. - 2012 IEEE Symp. Electr. Electron. Eng. EEESYM 2012, pp. 98-101, 2012.

[7] J. Lee, P. Quy, J.-I. Kim, L.-W. Kang, A. Seo, and H. Kim, "A Collaborative Virtual Reality Environment for Molecular Biology," 2009 Int. Symp. Ubiquitous Virtual Real., pp. 68-71, 2009.

[8] A. Y. u. Gital, A. S. Ismail, H. Chiroma, and A. Abubakar, "TCP Skudai: A high performance TCP variant for Collaborative Virtual Environment systems," Proc. - 6th Int. Conf. Inf. Commun. Technol. Muslim World, ICT4M 2016, pp. 118-121, 2017.

[9] A. Mukhopadhyay and A. Chattopadhyay, "Computer Graphics," Punjab Tech. Univ., p. 186, 2006.

[10] D. Herumurti, A. Yuniarti, I. Kuswardayan, W. Nurul, R. R. Hariadi, N. Suciati, and M. G. Manggala, "Mixed reality in the 3D virtual room arrangement," 2017 11th Int. Conf. Inf. Commun. Technol. Syst., pp. 303-306, 2017.

[11] C. Christou, "Virtual Reality in Education," Affect. Interact. Cogn. Methods E-Learning Des., pp. 228-243, 2010.

[12] R. P. Sharma and G. K. Verma, "Human Computer Interaction using Hand Gesture," Procedia Comput. Sci., vol. 54, no. August, pp. 721-727, 2015.

[13] W. R.Sherman and A. B.Craig, Understanding Virtual Reality: Interface, Application, and Design. 2003.

[14] J. Kjeldskov, "Interaction: Full and Partial Immersive Virtual Reality Displays," Aalborg Univ. Dep. Comput. Sci., pp. 587-600, 2001.

[15] E. J. Gindis and R. C. Kaebisch, "Spotlight On: Interior Design," Up Run. with AutoCAD® 2018, pp. 169-171, 2018.

[16] R. Zhang, Z. Xu, and X. Wang, "Application research on design ethics - The feasibility research of interior design for parent-child communication," World Autom. Congr. Proc., vol. 2016-Octob, 2016.

[17] C. Chuanrong and T. Hengliang, "The Application of Digital Technology in Interior Design Education," 2016 Eighth Int. Conf. Meas. Technol. Mechatronics Autom., pp. 688-691, 2016.

[18] C.-S. Chan, "Virtual Reality in Architectural Design," Caadria, vol. 97, no. February, pp. 1-10, 1997.

[19] H. Zhao, A. R. Swanson, A. S. Weitlauf, Z. E. Warren, and N. Sarkar, "Hand-in-Hand: A CommunicationEnhancement Collaborative Virtual Reality System for Promoting Social Interaction in Children With Autism Spectrum Disorders," IEEE Trans. Human-Machine Syst., vol. 48, no. 2, pp. 1-13, 2018.

[20] G. Bujdoso, O. C. Novac, and T. Szimkovics, "Developing cognitive processes for improving inventive thinking in system development using a collaborative virtual reality system," 8th IEEE Int. Conf. Cogn. Infocommunications, CogInfoCom 2017 - Proc., vol. 2018-Janua, no. CogInfoCom, pp. 79-84, 2018.

[21] P. Kaleja and M. Kozlovská, "Virtual Reality as Innovative Approach to the Interior Designing," Sel. Sci. Pap. - J. Civ. Eng., vol. 12, no. 1, pp. 109-116, 2017.

[22] K. Chalil Madathil and J. S. Greenstein, "An investigation of the efficacy of collaborative virtual reality systems for moderated remote usability testing," Appl. Ergon., vol. 65, pp. 501-514, 2017.

[23] S. Sharma, S. P. Rajeev, and P. Devearux, "An immersive collaborative virtual environment of a university campus for performing virtual campus evacuation drills and tours for campus safety," 2015 Int. Conf. Collab. Technol. Syst. CTS 2015, pp. 84-89, 2015.

[24] S. Pick, S. Gebhardt, B. Weyers, B. Hentschel, and T. Kuhlen, "A 3D collaborative virtual environment to integrate immersive virtual reality into factory planning processes," 2014 Int. Work. Collab. Virtual Environ. 3DCVE 2014, pp. 41-46, 2015.

[25] P. Khanal, A. Vankipuram, A. Ashby, M. Vankipuram, A. Gupta, D. Drumm-Gurnee, K. Josey, L. Tinker, and M. Smith, "Collaborative virtual reality based advanced cardiac life support training simulator using virtual reality principles," J. Biomed. Inform., vol. 51, pp. 49-59, 2014.

[26] A. Strelzoff and T. Sulbaran, "Transformation of a Collaborative Virtual Reality Environment for Construction Scheduling to help individual with mental health issues," 38th ASEE/IEEE Frointiers Educ. Conf., pp. SAJ13SAJ18, 2008.

[27] M. Sourial, A. Elnaggar, and D. Reichardt, "Development of a virtual coach scenario for hand therapy using LEAP motion," FTC 2016 - Proc. Futur. Technol. Conf., no. December, pp. 1071-1078, 2017.

[28] Redzuan, F., Khairuddin, A. N. A., \& Daud, N. A., "Emotional augmented reality-based mobile learning design elements: A kansei engineering approach," Indonesian Journal of Electrical Engineering and Computer Science, vol. 14, no.1, pp. 413-420, 2019.

[29] M. Kassim and M. N. H. M. Said, "Data analytics on interactive indoor cycling exercises with virtual reality video games," 2018 4th International Conference on Control, Automation and Robotics (ICCAR), Auckland, 2018, pp. 321-326.

[30] S. H. B. M. Hashim, M. B. Ismail, H. B. A. Manaf and F. A. B. Hanapiah, "Framework of virtual reality game on dual cognitive task for stroke rehabilitation," 2018 IEEE Symposium on Computer Applications \& Industrial Electronics (ISCAIE), Penang, 2018, pp. 114-118.

[31] N. A. Zulkanain and E. E. A. Rahim, "A Guideline for the Development of Blended Learning Platform Based on the Observation of Students' Reaction in a Virtual World," 2017 10th International Conference on Developments in eSystems Engineering (DeSE), Paris, 2017, pp. 115-119. 